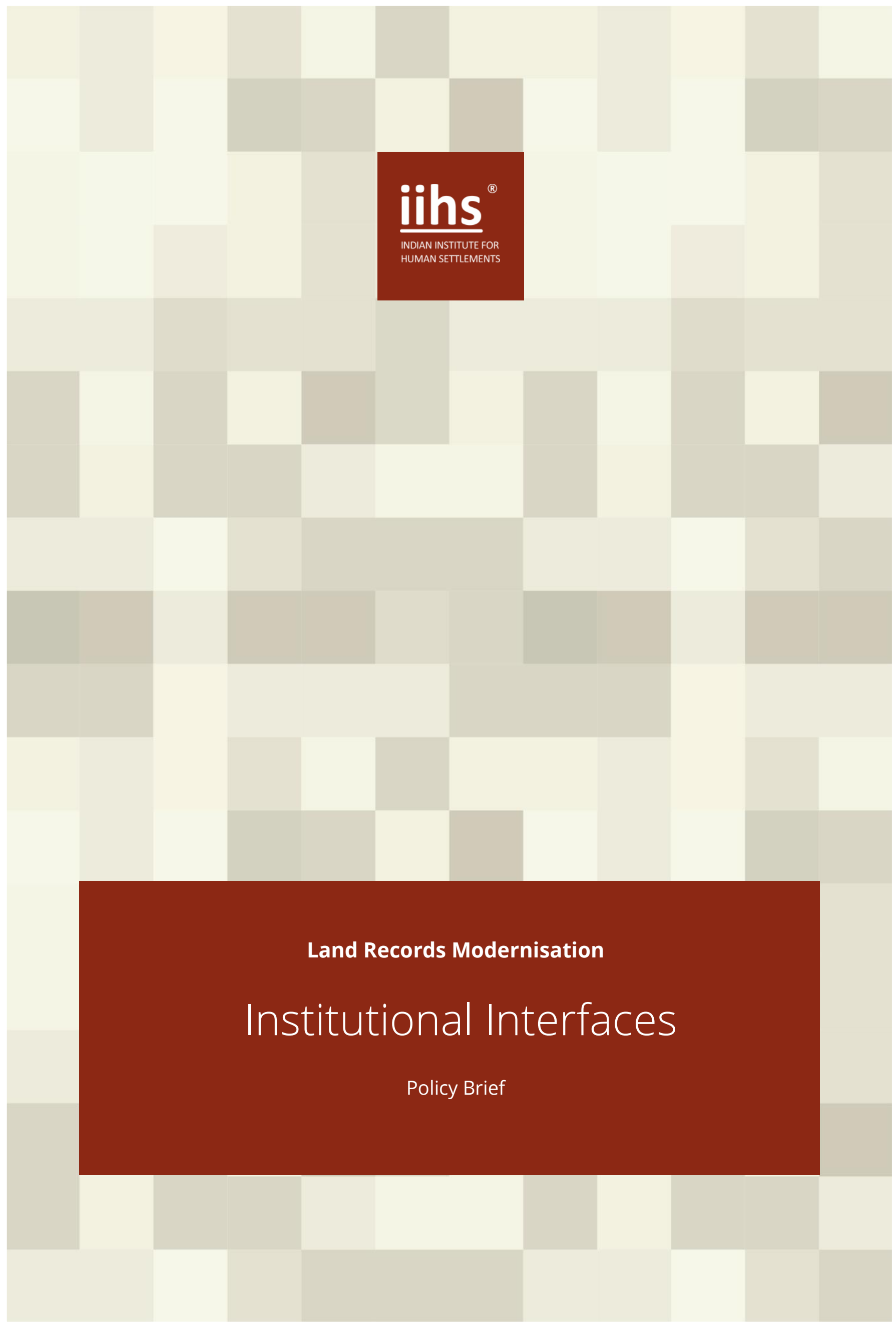




\section{LAND RECORDS MODERNISATION: INSTITUTIONAL INTERFACES}

\section{Institutional Framework and Coordination}

Within each Indian state, analysing the institutional framework governing land records is imperative. Various stakeholders that are either directly involved in or linked to land records management include:

- Revenue and Registration Departments: The core departments in charge of land records, and responsible for record creation and maintenance.

- Urban Land Administration Institutions: Urban institutions regulating land and its usage

- Other Stakeholders: These do not administer any control over land, but have an impact on the records, and vice versa (such as Judiciary and banks and financial institutions)

- Citizens: End-users of land records, and associated controls and services

The coordination of these institutions amongst themselves, and their inter-linkages to others, are important for a comprehensive and seamless records system. This coordination can be achieved either through merging of departments at state-level, assigning multiple functions to same officials, or through use of technology.

\section{Revenue and Registration Departments}

Land Records issues across India are the responsibility of three state-level departments:

1. Revenue Department: Maintaining land records regarding ownership, tenure, extent, and features of land, among others.

2. Stamps and Registration Department: Registration and levy of duties on deeds related to transfers of land and property.

3. Survey and Settlement Department: Carrying out extensive surveys and creating records in this regard. In some states, it is also responsible for maintaining and updating these spatial records.

It is significant to note that these departments are not mutually exclusive of one another in terms of their functioning, as there is a requirement for institutional coordination between them. In certain states (e.g. Gujarat and Karnataka), either two or all three functions are merged at the state-level for coordinated decision-making, followed by separate officials for each function. Some other states have merged the departments completely such that multiple functions are vested in the same official up to the field-level. For example, in Haryana and Himachal Pradesh, the sub-registrar (registration function) is also the Tahsildar (revenue and record function). Such mergers promote efficiency and reduce difficulties that arise out of inter-institutional coordination (inconsistent data sets, poor sharing of information, incoherent policies/ processes). It also reduces the scope for fraudulent transactions as the inspection and registration functions are vested with the same official.

Technology has a crucial role to play in integration of revenue related functions. In Karnataka, this has been achieved through the 'J-slip' (between registration and mutation) and Integrated Mutation Phodi (between mutation and spatial record updating). In Gujarat, all registrations for agricultural land automatically lead to a kachi mutation entry, which is certified or rejected after due process of inviting objections for 30 days, and their disposal. Similarly, in Haryana, any registration under Haryana Registration Information System (HARIS) links to the Haryana Land Records Information System (HALRIS) platform to provide inputs on a subsequent mutation. Likewise, HARIS obtains information in order to verify the genuineness of a claim of ownership by the seller of a property, though the implementation of this HARIS-HALRIS Bridge remains partial. In Bihar and Himachal Pradesh, BhuNaksha is proposed to integrate textual records (land records department) with spatial records (survey department).

\section{Urban and Peri-Urban Land Administration Institutions}

While the Revenue Department is the primary institution dealing with land records, there are multiple institutions within urban and peri-urban areas, which regulate land and control its usage. These include: 
1. Town and Country Planning and Development Authorities: Assigning land uses (including change of land use), development controls, granting development permissions, licenses.

2. Municipal Authorities/Urban Local Bodies: Maintaining property register and collecting taxes.

3. Industrial Development/Housing/Slum Authorities: Acquire, own, develop and allot land.

4. Special Authorities: Control over land for specific purposes such as infrastructure provision, export promotion, real estate development.

These urban institutions, their jurisdictions and the records maintained by them, are mostly independent of the core land records system, as originally envisaged. Their overlapping and changing jurisdictions also lead to a lack of clarity and poor coordination, thus making the urban system difficult to navigate. This ambiguity often compromises the manner in which implementation is to take place. However, there are exceptions, for instance, in states like Himachal Pradesh, where the Revenue Department also maintains records for urban areas, there is some level of coordination in terms of defining jurisdictions and record maintenance. In Gujarat, under the town planning scheme mechanism, concerned authorities coordinate with Revenue Department to determine parcel level ownership data. Once the scheme is finalised, Revenue Department is required to update its records as per readjusted plots. Details of de facto implementation may vary depending on particular locations. Convergence of multiple roles in the same official can be followed even outside the Revenue Department, through deputations and additional charges, as observed in Haryana and Himachal Pradesh.

It is significant to note that the select study states do not have specific protocols or technological data bridges with linked departments such as urban local bodies or development authorities regarding changes in land use, conversion, building permissions, taxation records etc., in order to make the record more comprehensive. For example, in Himachal Pradesh, there is a scope to link the land use register (maintained Khasra number wise, by the Department of Town and Country Planning) or municipal jurisdiction (notified by urban local bodies in terms of Khasra numbers) with Records of Rights (RoR). Karnataka has introduced Bhu-Swadheen, which integrates data about land acquisition for different government agencies to the state's land records, but it is yet to be used extensively. Gujarat plans to provide e-Jamin log-in details to land-acquiring authorities in order to trigger mutations. Haryana Urban Development Authority (HUDA) has a property management system for 3.5 lakh users including encumbrance details, which can be shared and form an essential part of Haryana's land records system.

\section{Other Stakeholders}

1. Judiciary: Institutional coordination with the judiciary in the form of pending case updates/encumbrances is an essential element in improving records. The Department of Revenue, Himachal Pradesh had directed revenue officials to make entries of any litigation/disputes into the Jamabandis. However, this has not been practically implemented in the state.

In Himachal Pradesh, the Revenue Court Monitoring System has been proposed in order to provide litigation and encumbrance related information in relation to revenue cases and has the potential to be linked with HIMBHOOMI. However, this has not been taken further than the pilot stage in the state.

2. Banks: BHOOMI in Karnataka has technological bridges with the modern banking system (based on a user fee model), which enables the latter to verify land records, and vice versa update mortgage details in the encumbrances. Similarly, Gujarat has provided e-Jamin log-in details to banks, in order to facilitate direct updation of mortgage details in the RoR. Himachal Pradesh has enacted legislation in order to create a charge in favour of a bank and also contains provisions in relation to the entry of relevant information in the record of rights. Legislation such as the Kisan Passbook system provide for the creation of charge in cases of rural credit, where the banking system is critical. An effective land records system would also be in the best interest of banks and financial institutions, especially on matters of creating charge, and collateral for loans, creation of mortgage and so on. 


\section{Citizens and Access to Service}

The interaction between citizens and all the related institutions takes place at various levels. Right to Public Service legislations (coupled with technological initiatives) have led to significantly faster and time-bound services, especially in registration and mutation functions. Despite some progress by the states on certain fronts, the absence of clearly outlined protocols and functions, creates confusion for citizens whose interests play out in the de facto situation on the ground. Initiatives like the Lok Mitra Kendras and Sugam centres in Himachal Pradesh serve as examples of possible models to assist citizens in availing services at decentralised levels. These display a degree of institutional coordination with either governmental/private assistance thereby making information and records more readily available using technology. But in spite of Right to Information legislation, much more needs to be done to provide real-time, updated access to comprehensive land records information, including details such as Change of Land Use permissions etc.

\section{Lack of Inter-Institutional Bridges for Data Sharing}

1. Ownership: Institutional land acquisition, allotment, transfers

2. Possession: Long- term leases and other official tenure categories on government land

3. Extent: Institutional and government owned land banks

4. Classification: Prescribed and restricted use zones (planning zones, forest areas, wetlands, etc.)

5. Encumbrances: Mortgages

Improved institutional integration is likely to be an essential requirement for a proposed revamped Digital India Land Records Modernisation Programme (DILRMP). The current focus on digitisation of records would be useful, provided such records are of a more comprehensive nature and take into account the challenges and opportunities of respective stakeholders. Greater coordination and integration of information with urban agencies as well as stakeholders such as the judiciary and banks will help ensure details such as land use changes and mapping along with encumbrances on property are included in records.

The Jawaharlal Nehru National Urban Renewal Mission, as per its optional reforms agenda, had suggested a property title certification system in urban local bodies be introduced. However, only 23 of the 65 urban local bodies have successfully initiated such systems (although the extent of implementation is unclear) (MoUD, 2014)i. Given the predominance of the Revenue Department in land records management, better coordination and integration with urban local bodies in introducing these reforms will be useful.

\footnotetext{
${ }^{\text {i }}$ As on 31 st Jan 2014, retrieved from http://jnnurm.nic.in/
} 